\title{
3D contour detection: a non-photorealistic rendering method for the analysis of Egyptian reliefs
}

Francesca Valentina Luisa Lori ${ }^{1, *}$ \& Corinna Rossi ${ }^{1}$

${ }^{1}$ Department of Architecture, Politecnico di Milano, Italy

* Author for correspondence: francescavalentina.lori@polimi.it

This paper presents the results of a non-photorealistic rendering technique applied to three different types of reliefs from the ancient Egyptian tomb of Meryneith at Saqqara.

Keywords: Egypt, reliefs, epigraphy, non-photorealistic rendering, 3D contour detection

\section{Introduction and state of the art}

In the field of Egyptology, the most complete and detailed method of recording epigraphy has been outlined by the Epigraphic Survey of the Oriental Institute of Chicago. Based on an everevolving combination of handmade drawings, hardware and software, it produces extremely refined line drawings, able to convey a large amount of information thanks to precise graphic standards (Vertés \& the Epigraphic Survey 2014). In parallel, researchers have, in recent years, begun to investigate how to extract line drawings from 3D models (DeCarlo et al. 2003; DeCarlo \& Rusinkiewicz 2007; Ohtake et al. 2004; Rusinkiewicz et al. 2006, 2008; Judd et al. 2007), including some experiments in the epigraphic field (Kolomenkin et al. 2013; Tokovinine \& Fash 2014; Berkiten et al. 2015; Carrero-Pazos \& Espinosa-Espinosa 2018). In an attempt to bridge these two approaches, we present the results of our investigation into the best combination of tools to automatically achieve computer-generated line drawings that would be, at the same time, directly based on the 3D geometry of the reliefs, and useful for subsequent epigraphic studies, especially monitoring erosion.

\section{Methodology}

We applied non-photorealistic rendering techniques (Rusinkiewicz et al. 2008) to the 3D models of a selection of reliefs from the tomb of Meryneith (Saqqara, Egypt) using real-time suggestive contours (RTSC) software (https://gfx.cs.princeton.edu/proj/sugcon), which collects all the basic algorithms commonly used to extract shapes from $3 \mathrm{D}$ surfaces in the fields of engineering and gaming (Figure 1).

We tested the software on different reliefs from the tomb (Figure 2): a well-preserved sunken relief (R22-23-24, Figure 3A), a partly eroded sunken relief (R32, Figure 3B) and a rather faded raised relief (R14, Figure 3C). The images were all surveyed in 3D employing photogrammetry, using a Canon EOS 5D reflex camera, without flash, ISO 100, f8 settings

Received: 10 February 2020; Revised: 19 March 2020; Accepted: 8 April 2020

(C) The Author(s), 2020. Published by Cambridge University Press on behalf of Antiquity Publications Ltd 


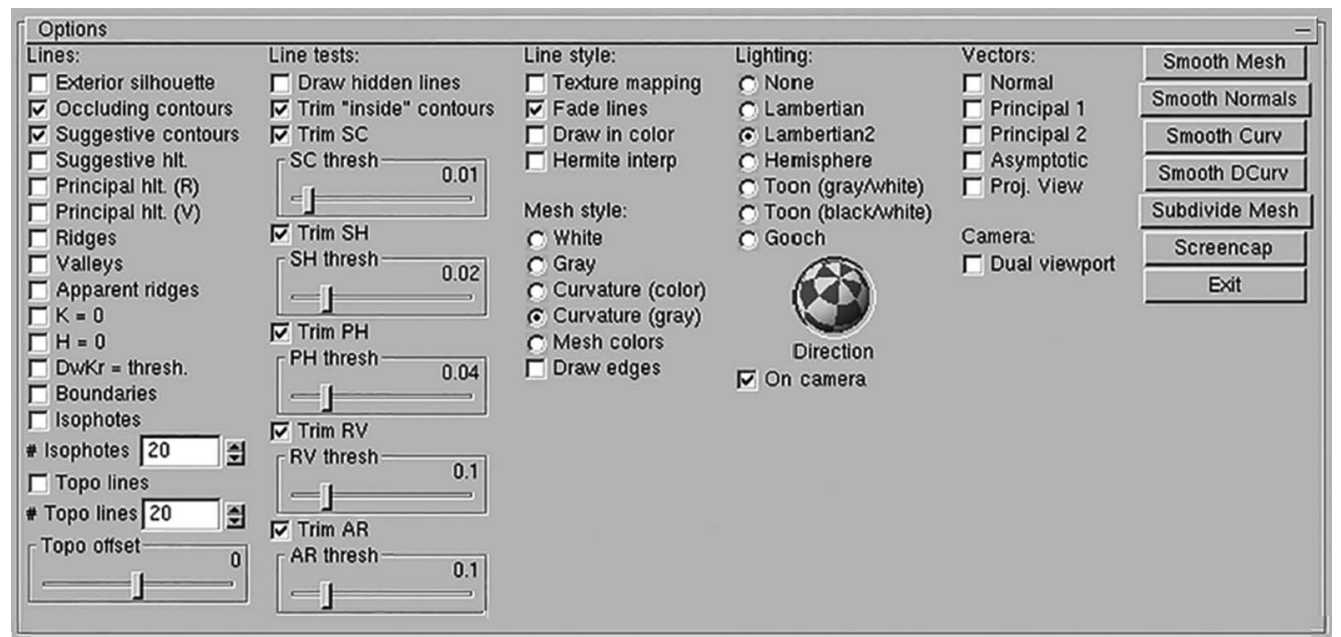

Figure 1. RTSC software options panel. Screenshot by Francesca Lori. Software developed by A. Finkelstein, S. Rusinkiewicz, M. Burns, J. Klawe, D. DeCarlo, A. Santella. All the RTSC files are distributed under the GNU General Public Licence.

and $35 \mathrm{~mm}$ focal distance, and aligned using Agisoft Metashape software. We proceeded to test them all using the RTSC filters in order to identify which combination would produce a clearer result.

\section{Results}

Our tests measured 'ridges', which correspond to the points where the surface bends sharply from top to bottom (shown in blue in Figures 4-6A), and 'valleys', the points at which the

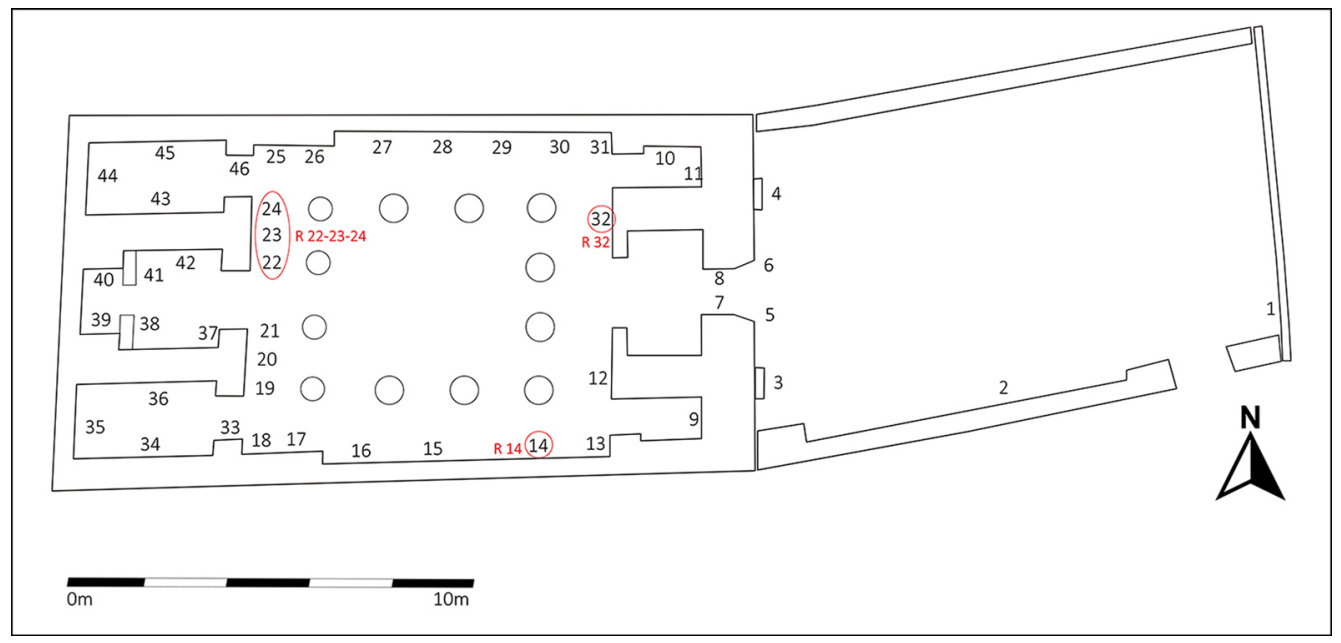

Figure 2. Plan of the tomb of Meryneith, showing the position of all of the reliefs; the circled numbers indicate reliefs analysed in this paper. Plan redrawn by Francesca Lori based on a photograph from the book The Tomb of Meryneith at Saqqara (M.J. Raven \& R. van Walsem; Chapter 3: The Architecture, fig.III.3).

(C) The Author(s), 2020. Published by Cambridge University Press on behalf of Antiquity Publications Ltd 


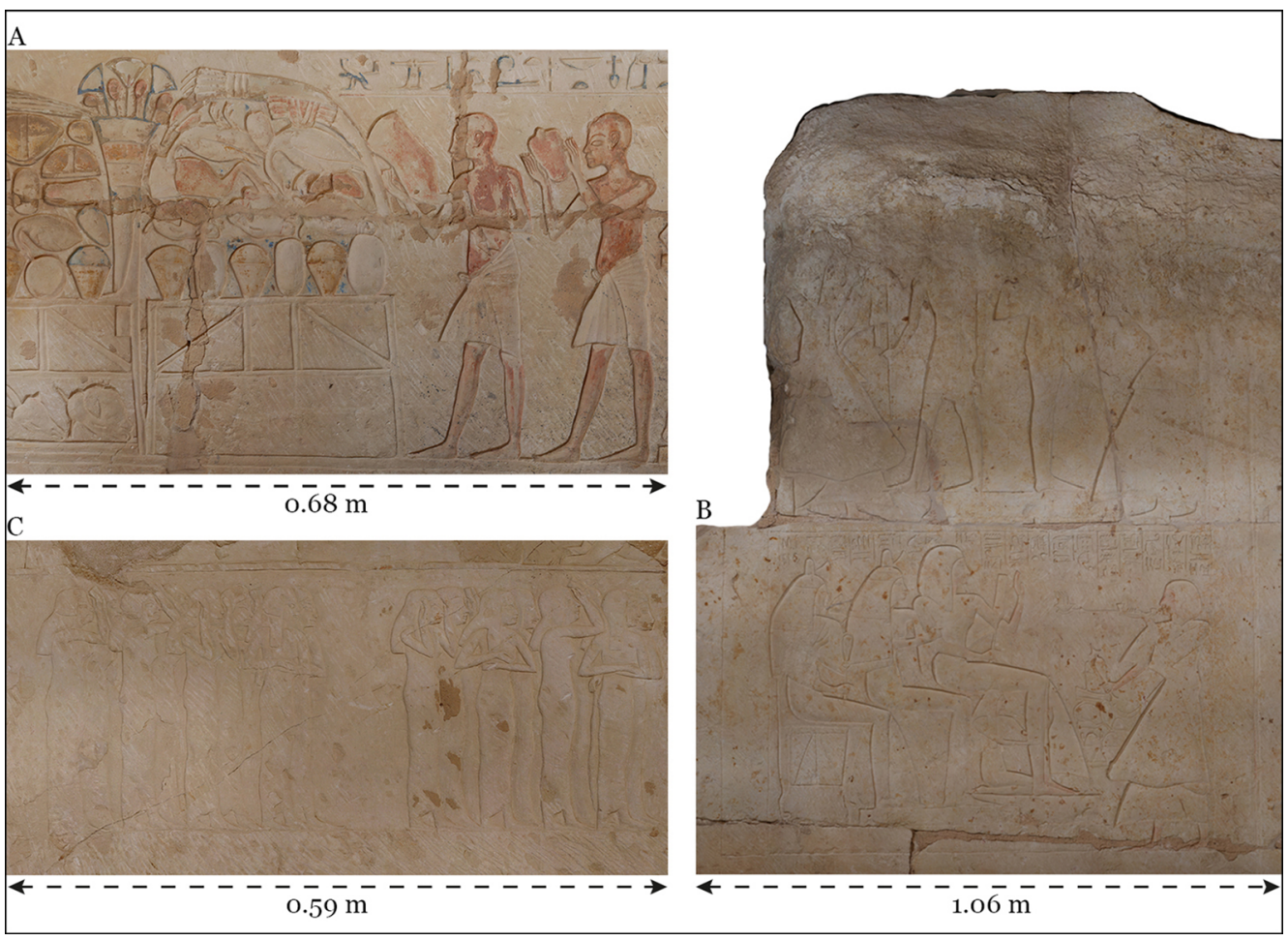

Figure 3. A) Orthophotograph of a detail of R22-23-24; B) orthophotograph of a detail of R32; C) orthophotograph of a detail of R14. Photographs by Francesco Fassi, Alessandro Mandelli and Luca Perfetti (3D Survey Group, Politecnico di Milano). Orthophotographs courtesy of the Turin-Leiden mission to Saqqara (Museo Egizio, Torino and Rijksmuseum van Oudheden, Leiden).

surface bends sharply from bottom to top (shown in brown in Figures 4-6A). According to our results, ridges are fundamental in revealing details such as the folds of the skirts of R22-23-24, while valleys best reveal the outline of both sunken and raised reliefs. In general, varying the threshold settings can be useful to highlight or tone down some elements (e.g. the higher the threshold, the lower the background noise). The combination of ridges and valleys is very useful in visualising the angle of the engravings (the longer the distance, the lower the slope), but can also generate rather confusing line drawings (Figures 4-6A).

The use of the Lambertian lighting function proved to be particularly interesting. In general, as radiance scaling and ambient occlusion demonstrate, artificial lighting can be useful to analyse extremely faded or damaged reliefs (as the upper part of R32). In particular, as the standard convention in the representation of reliefs places the hypothetical sun always coming from the upper-left corner at $45^{\circ}$, we set the light as coming by default from that direction (as shown in Figures 4-6B).

The RTSC software can also draw isophotes, curves connecting points of equal brightness (Figures 4-6C). The resulting images convey a very effective description of the geometry of the surfaces; however, as they already consist of a large number of lines, if combined with valley and/or ridges, they generate a wealth of information that is detrimental to a detailed study of the figures.

(C) The Author(s), 2020. Published by Cambridge University Press on behalf of Antiquity Publications Ltd 


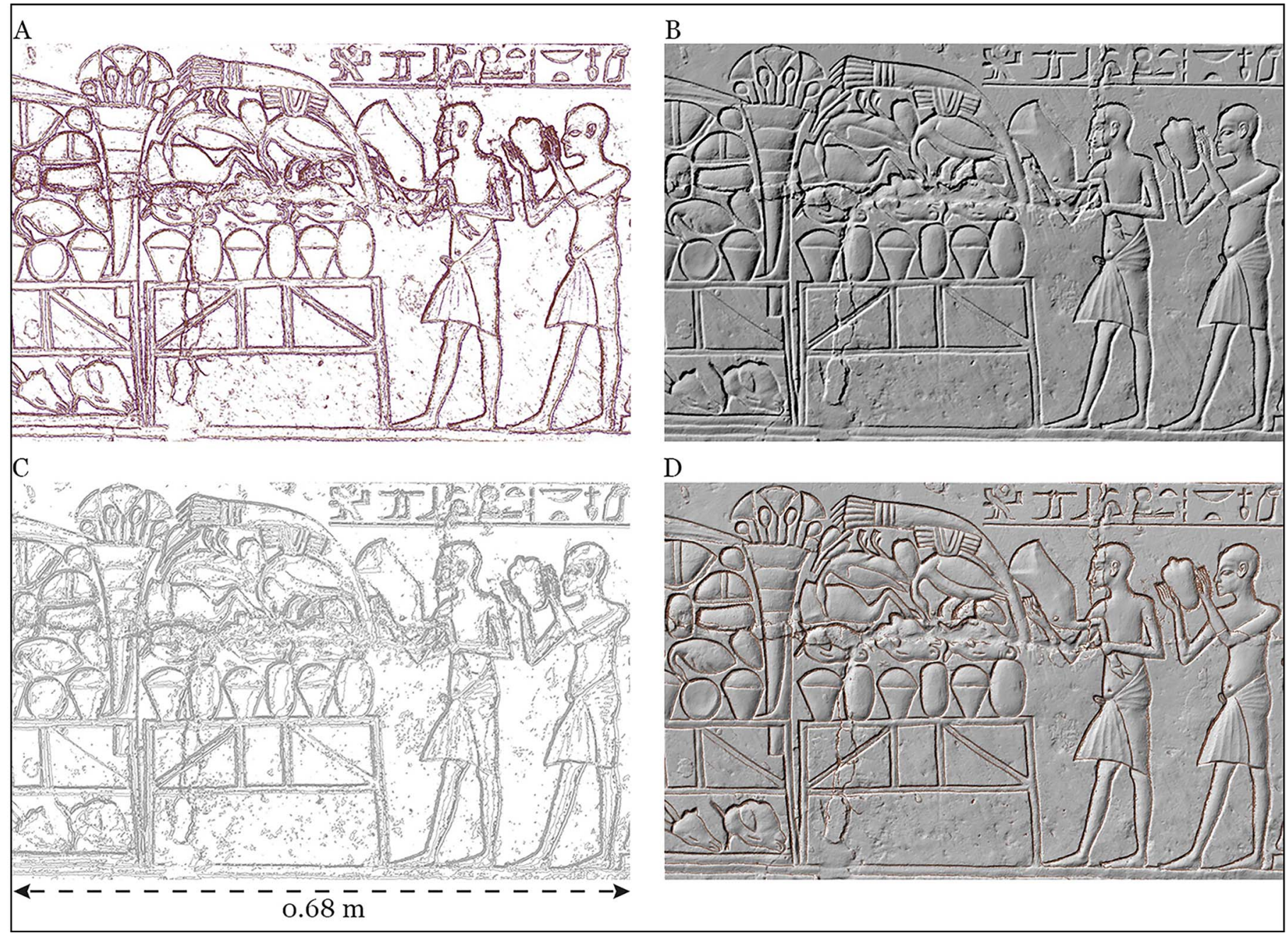

Figure 4. Detail of R22-23-24 (sunken relief): A) ridges shown in blue, and valleys in brown (threshold: $0.138 ; B$ ) with Lambertian lighting from $45^{\circ}$ upper left; C) isophotes drawing (density: 4); D) 3D CoDe: Lambertian lighting from $45^{\circ}$ upper left and valleys shown. Image by Francesca Lori; $3 D$ models optimisation by Politecnico di Milano; $3 D$ models courtesy of the Turin-Leiden mission to Saqqara (Museo Egizio, Torino and Rijksmuseum van Oudheden, Leiden). 


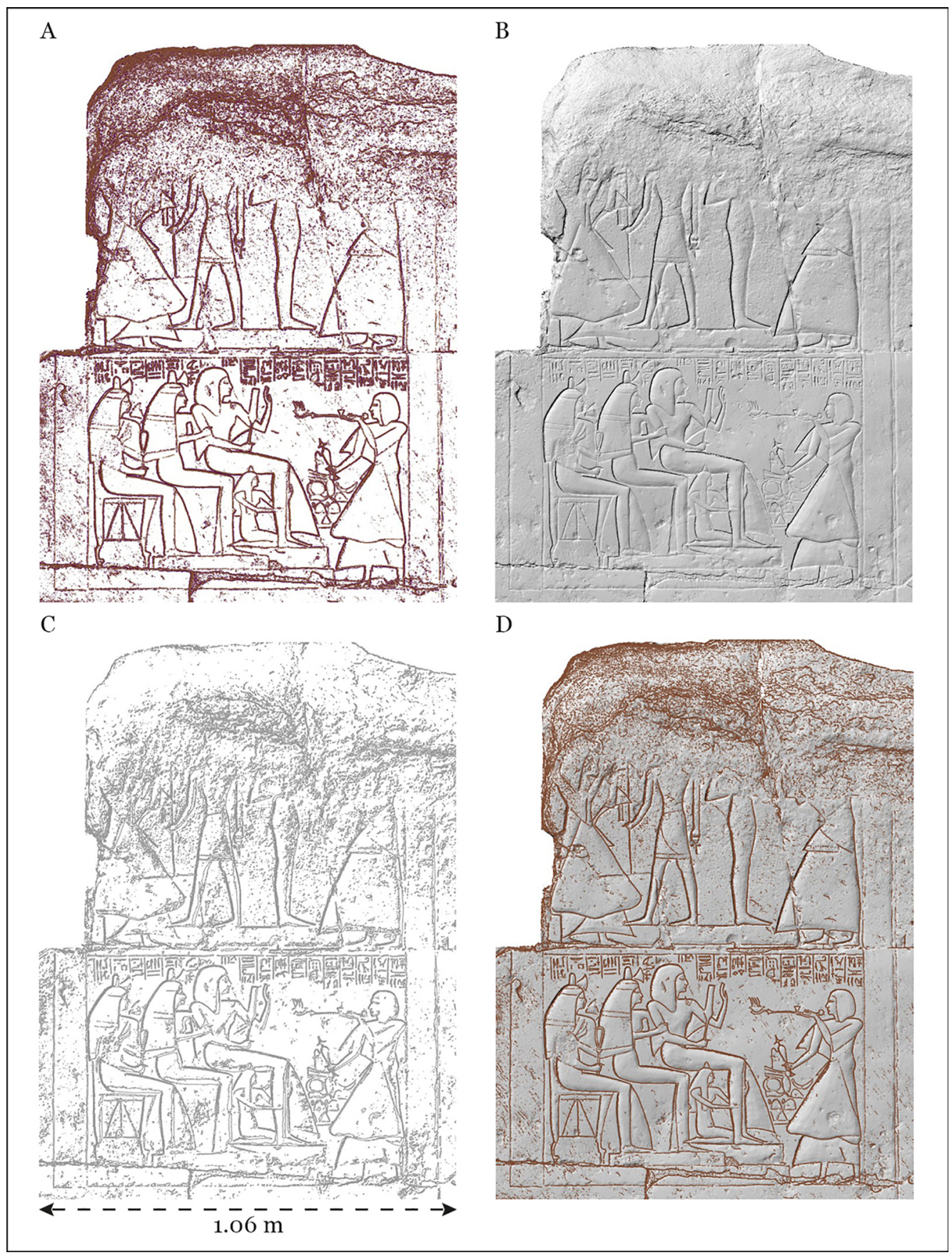

Figure 5. Detail of R32 sunken relief: A) ridges shown in blue and valleys in brown (threshold: 0.174); B) with Lambertian lighting from $45^{\circ}$ upper left; C) isophotes drawing (density: 3); D) 3D CoDe: Lambertian lighting from $45^{\circ}$ upper left and valleys shown. Image by Francesca Lori; $3 D$ models optimisation by Politecnico di Milano; $3 D$ models courtesy of the Turin-Leiden mission to Saqqara (Museo Egizio, Torino and Rijksmuseum van Oudheden, Leiden).

(C) The Author(s), 2020. Published by Cambridge University Press on behalf of Antiquity Publications Ltd 

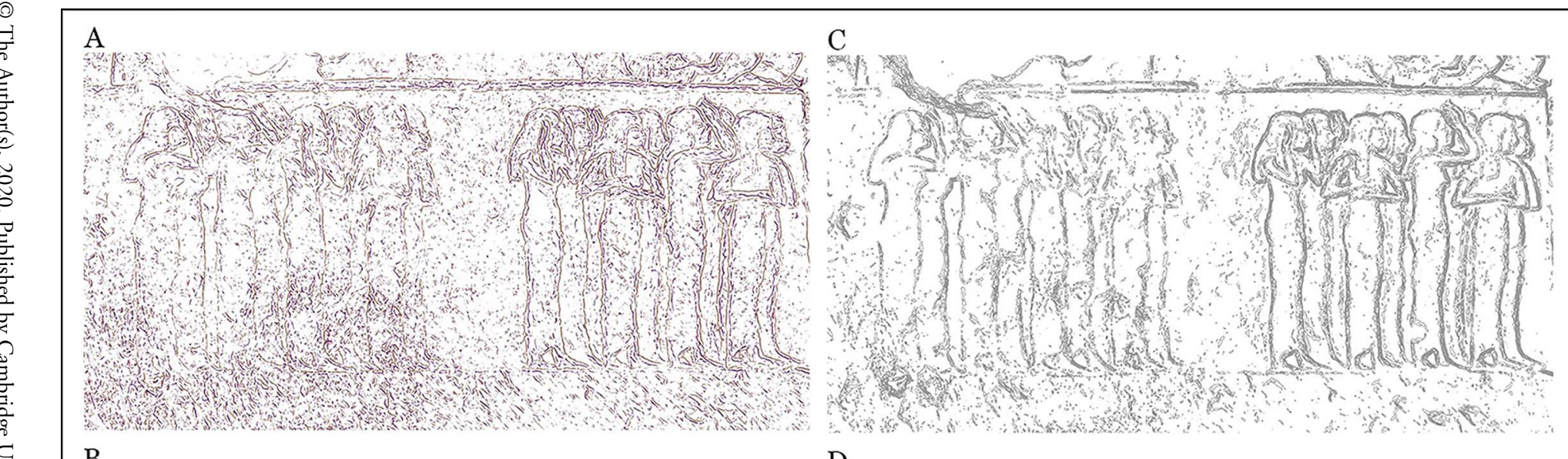

B

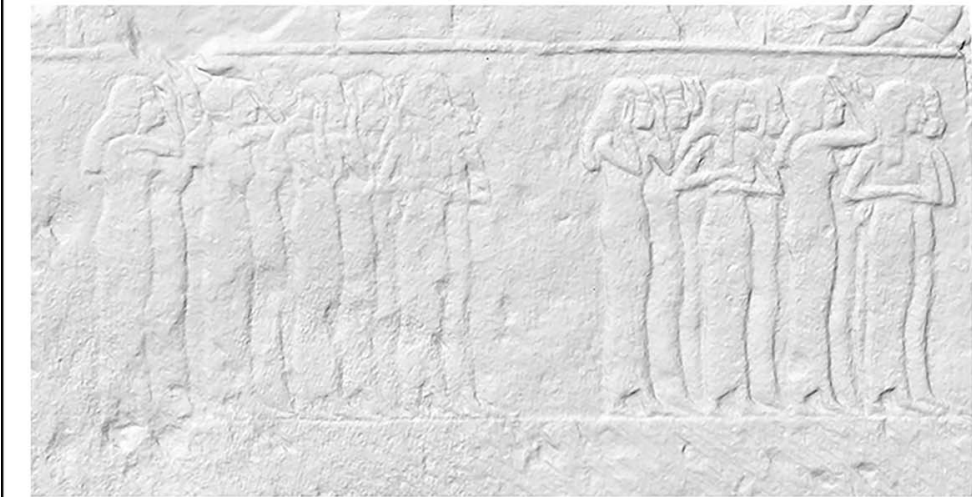

$\mathrm{D}$

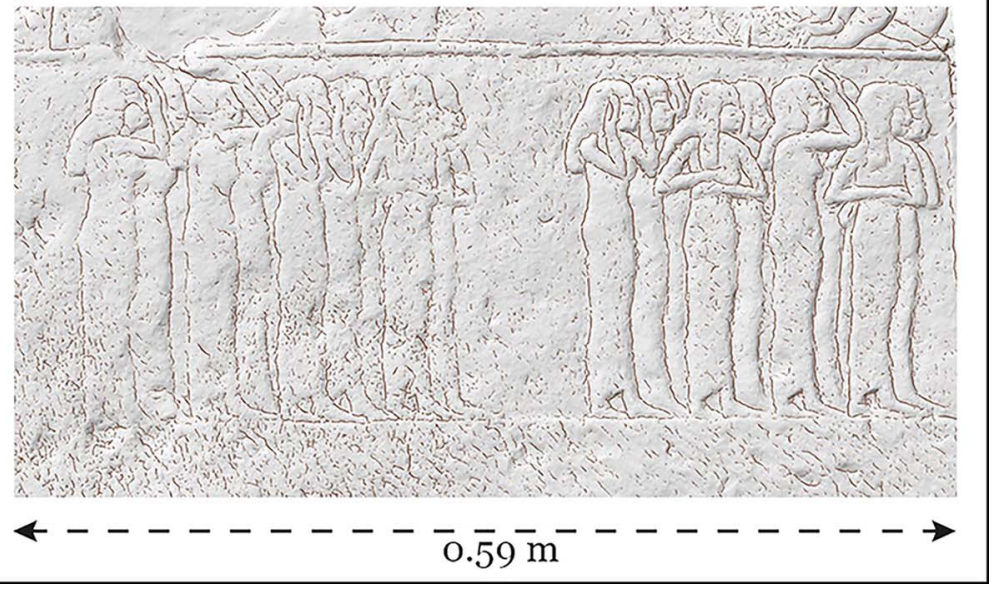

Figure 6. Detail of R14 raised relief: A) ridges shown in blue and valleys in brown (threshold: 0.1 ); B) with Lambertian lighting from $45^{\circ}$ upper left; C) isophotes drawing (density: 44); D) 3D CoDe: Lambertian lighting from $45^{\circ}$ upper left and valleys shown. Image by Francesca Lori. 3D models optimisation by Politecnico di Milano; 3D models courtesy of the Turin-Leiden mission to Saqqara (Museo Egizio, Torino and Rijksmuseum van Oudheden, Leiden). 


\section{Conclusions}

In order to automatically obtain a line drawing directly based on the $3 \mathrm{D}$ geometry of the reliefs that can be used as a basis by epigraphists, the most efficient among the available tools appears to be the combination of Lambertian light and valley contours offered by RTSC (Figures 4-6D). The advantage of this combination is the clarity of the resulting image; an additional benefit is its ability to reveal damaged or worn engravings (such as R32 and R14).

Isophotes can be useful, in parallel, to highlight faded reliefs by increasing the number of lines (as used on R14) and, subsequently, to monitor the degradation of the surface over time: repeated surveys might reveal a reduction of the perimeter of the 'islands' of points characterised by the same brightness, caused by progressive erosion.

We have named the procedure described here $3 \mathrm{D}$ contour detection (3D CoDe). It can be successfully used in its current form to achieve the results described above. As the mathematical algorithms applied by RTSC are designed to extract shapes from 3D objects, the procedure could be considerably improved if developed specifically for epigraphy, which is usually perpendicular to a flat surface and therefore could use a streamlined algorithm compared with those necessary for 3D complex objects. Another interesting research direction would be to focus on the potential of light and shadow rendering or using comparison between isophotes and meshes to monitor progressive erosion.

In general, 3D CoDe may support the work of archaeologists and epigraphists by providing a filter able to generate a representation that would be readable, geometrically correct and aligned to the basic epigraphic standards.

\section{Acknowledgements}

Thanks to Christian Greco, Co-Director of the joint Turin-Leiden mission to Saqqara (Museo Egizio, Torino and Rijksmuseum van Oudheden, Leiden), who suggested an investigation in this direction. Thanks to Lara Weiss, Co-Director of the mission, and to Szymon Rusinkiewicz for their support. The survey of the reliefs was the work of Francesco Fassi, Alessandro Mandelli and Luca Perfetti (3D Survey Group, Politecnico di Milano); the elaboration of the 3D models was undertaken by Simone Galli (Politecnico di Milano).

\section{Funding statement}

The research illustrated in this article is part of the project LIFE ('Living in a Fringe Environment'), funded by the European Research Council under the European Union's Horizon 2020 research and innovation programme (grant agreement 681673).

\section{References}

Berkiten, S., X. Fan \& S. Rusinkiewicz. 2015. Semi-automatic digital epigraphy from images with normals. Non-Photorealistic Animation and Rendering 2015: 91-102.

https://doi.org/10.2312/exp.20151182
Carrero-Pazos, M. \& D. Espinosa-Espinosa. 2018. Back to basics: a non-photorealistic rendering method for the analysis of texts from $3 \mathrm{D}$ Roman inscriptions. Antiquity Project Gallery 92 (364). https://doi.org/10.15184/aqy.2018.146 
DeCarlo, D. \& S. Rusinkiewicz. 2007. Highlight lines for conveying shape. Non-Photorealistic Animation and Rendering 2007: 63-70. https://doi.org/10.1145/1274871.1274881

DeCarlo, D., A. Finkelstein, S. Rusinkiewicz \& A. Santella. 2003. Suggestive contours for conveying shape. ACM Transactions on Graphics 22: 848-55.

https://doi.org/10.1145/882262.882354

Judd, T., F. Durand \& E. Adelson. 2007. Apparent ridges for line drawing. ACM Transactions on Graphics 26: article 19. https://doi.org/10.1145/1276377.1276401

Kolomenkin, M., I. Shimshoni \& A. Tal. 2013. Multi-scale curve detection on surfaces, in Proceedings of the 2013 IEEE Computer Society conference on computer vision and pattern recognition: 225-32. Piscataway (NJ): Institute of Electrical and Electronics Engineers. https://doi.org/10.1109/CVPR.2013.36

Ohtake, Y., A. Belyaev \& H. Seidel. 2004. Ridge-valley lines on meshes via implicit surface fitting. ACM Transactions on Graphics 23: 609-12. https://doi.org/10.1145/1015706.1015768

Rusinkiewicz, S., M. Burns \& D. DeCarlo. 2006. Exaggerated shading for depicting shape and detail. ACM Transactions on Graphics 25: 1199-205. https://doi.org/10.1145/1141911.1142015

Rusinkiewicz, S., F. Cole, D. DeCarlo \&

A. Finkelstein. 2008. Line drawings from 3D models. Available at: http://gfx.cs.princeton.edu/proj/sg08lines/ (accessed 24 September 2020).

Tokovinine, A. \& B. Fash. 2014. Epigraphy in 3D: digital photogrammetry and publication of Classic Maya inscriptions. Paper presented at the symposium '3D Tools for Archaeological Research in Ancient Americas', Society for American Archaeology $79^{\text {th }}$ Annual Meeting, Austin, Texas, 25 April 2014.

Vertés, K. \& the Epigraphic Survey. 2014. Digital epigraphy. Chicago (IL): Oriental Institute of the University of Chicago.

(C) The Author(s), 2020. Published by Cambridge University Press on behalf of Antiquity Publications Ltd 